\title{
GUIDELINES FOR IMPROVING THE ENVIRONMENTAL FRIENDLINESS AND SAFETY OF RAILWAY TRANSPORT FREIGHTS OF DANGEROUS CARGO WITHIN THE REPUBLIC OF BULGARIA
}

\author{
Svetla Tzvetkova ${ }^{1}$
}

\begin{abstract}
The ecological, social and safety implications of railway transport freights of dangerous cargo require addressing the fact that while hazardous substances are an integral part of people's way of life in the modern age, they can adversely and severely affect living standards. The incorrect storage, transportation, loading and unloading of dangerous cargo could pose a serious threat to people, their property and the environment. In recent years, accidents involving the transportation of dangerous cargo have become more frequent. An indicative example in this regard is the explosion of several cisterns containing propanebutane at the railway station in the village of Hitrino - a severe accident which killed seven people and injured ninety-nine. This can be classified as an ecological and social disaster. The present article is a response to a multitude of such accidents and to issues such as poor conditions of railway infrastructure, outdated and obsolete rolling stock, lack of qualified personnel and lack of measures for limiting harmful impact on the environment. The goal of this paper is to justify the necessity for improving the environmental friendliness and safety of railway transport freights of dangerous cargo within the Republic of Bulgaria and to indicate specific measures and guidelines to this effect. The topicality of the paper is supported by the probability of reoccurrence of these ecological disasters with irreversible consequences for people and the environment.
\end{abstract}

JEL Classification Numbers: R40, R41, R48, R49, DOI: https://doi.org/10.12955/peb.v1.31

Keywords: rail transport, transport of dangerous goods, guidelines for improving the safety of transport of dangerous goods

\section{Introduction}

The fundamental nature of the carriage of dangerous goods, due to inherent risks, requires assessing and guaranteeing the safety of transport processes and environmental protection. Since it is among the most profitable in the transport sector, this type of carriage is an appealing activity for the majority of the larger transport companies (Zhelezov et al., 2010). The carriage of dangerous goods by railway transport is an inseparable part of modern industry and people's lives. However, the hazardous substances and chemicals associated with this activity adversely affect living standards as well as the environment. Dangerous substances and chemicals make up a large percentage of the total quantity of railway cargo freights, and any disregard for safety during their transportation, storage, loading and unloading could pose a serious threat for people and the environment. Nowadays people in Europe, including Bulgaria, are witnesses to the consequences of damages caused by incidents or phenomena such as the Chernobyl disaster, acid rain, air heating, increased $\mathrm{CO}_{2}$ levels, effects of sulfur and other rare but severe traffic accidents involving dangerous cargo. It is undeniable that while the accidents and disasters related to railway transport in the Republic of Bulgaria are few, they are grand in scope, causing multiple human casualties and inflicting significant damage to the environment. We can list three incidents that have received serious public outcry as notable examples in this regard. The first incident occurred on August 14, 2013 wherein a "Gastrade" trainset transporting tanks filled with propane-butane caught fire in the vicinity of the Ezerovo village of the Beloslav municipality. The incident occurred during the transference of gas from a railway tank to a truck tanker, resulting in one casualty and eleven injured people. The investigation concluded that the incident was caused by the lack of discipline and responsibility on the part of two workers. The second such incident occurred on July 12, 2014 wherein the Sofia-Varna express train went off the rails in the vicinity of the Kaloyanovetz train station of the Stara Zagora municipality, resulting in the death of the motorman and dozens of injured people, with four people sustaining severe bodily injuries. Once again, a lack of responsibility was cited, this time on the part of the assistant-motorman who was operating the train. The third incident occurred on December 10, 2016 wherein the Shumen village of Hitrino was shaken by a powerful explosion. A train set transporting tanks filled with propane-butane and propylene went off the rails at the village's train station, located in its center. One of the tanks was overturned and ruptured, causing the gas that leaked out to go off in an enormous inferno, resulting in seven casualties, multiple injured people and an incinerated village. The village's residents have sustained severe physical and psychological traumas that will surely take them at least a generation to overcome and forget. The potential for reoccurrence of similar ecological disasters that can have irreparable consequences for people's property and health

\footnotetext{
${ }^{1}$ Department - "Economics of Transport and Energy", Faculty - "Economics of Infrastructure", University of National and World Economy - Sofia, Bulgaria, svetlatzvetkova@abv.bg
} 
necessitates strict control in the areas of overall organization and management of dangerous cargo freights, the condition of railway tracks and rolling stock, as well as storage, loading and unloading activities. Meticulous implementation of various specific measures in terms of protection from fires, explosions or infections should be planned, controlled and enforced, with employee discipline and responsibility better monitored. Increasing safety and reducing harmful environmental influence during railway transportation of dangerous goods depends on multiple factors. The present article analyzes some of the main ones, namely the condition of railway tracks, the rolling stock and staff.

\section{Normative Framework of Transporting Dangerous Cargo by Railway Transport}

The national primary and secondary legal regulations in the field of dangerous cargo transportation are based on and conform to international and European legislative decrees. The purpose of the convention concerning International Carriage by Rail (COTIF), signed on May 9, 1980 in Bern (ratified with Decree No 1439 by the State Council, SN, Issue 46, 1982), and effective in Bulgaria since May 1, 1985, was to advance and facilitate international railway traffic and has been in effect for the Republic of Bulgaria since May 1, 1985. In order to fulfill its goal, the convention has established legal regimes by way of treaties for passenger and cargo freights in a direct international railway message, including additional freights that use other vehicles. Treaties have been established for the organization and control of security at sites, enterprises and special cargo within the transport infrastructure and railway transport. Due to the particular threat to people's lives and ecological security, a special document has been formulated with regards to arranging freights for radioactive cargo. The convention for physical protection of nuclear materials stipulates the levels of physical protection during international freights of nuclear materials (SN, Issue 44, 1987). Separate rules of the Treaty for International Railway Cargo Transportation (supplement to CIM), which have been defined as uniform, have been laid out to articulate payment for treaties involving railway cargo transportation wherein the reception site for the cargo and the intended delivery site of the cargo are located in different member states, regardless of the headquarters and nationality of the parties in the freight treaty. The Regulations Concerning the International Carriage of Dangerous Goods (RID) determines the requirements for international transportation of dangerous cargo, listed in a COTIF Appendix. The following categories of dangerous goods have been defined: dangerous goods banned from international transportation and dangerous goods approved for international freights. Additionally articulated are freight conditions in terms of classification, use of canisters, tanks and consignment procedures, requirements involving the construction, testing and approval of canisters and tanks, as well as the use of transport vehicles. In addition to the generally valid international documents, the transportation of dangerous goods is also subject to regulation by EU authorities (Nikolov, 2015). The purpose of adopting common rules and requirements for the international carriage of dangerous goods is to create safety conditions and to protect human lives, the environment and the traffic from the effect of hazardous substances (Ganev et al., 2011).

\section{Analyzing safety during carriage of dangerous goods by railway transport}

\section{Analyzing the condition of railway tracks}

Since 2002 the railway infrastructure in the Republic of Bulgaria has been under the management of the 'Railway Infrastructure National Company' which provides licensed carriers with open access to the railway network. The level of electrification makes up $60 \%$ of its total length. Table 1 presents the total unfolded area of the railway network.

\begin{tabular}{|l|l|}
\hline Table 1. Total unfolded length of the railway network \\
\hline Railway network & Length \\
\hline Single railroads with regular spacing (1435 $\mathbf{~ m m})$ & $2906 \mathrm{~km}$ \\
\hline Double railroads with regular spacing & $1976 \mathrm{~km}$ \\
\hline Station tracks with regular spacing & $1439 \mathrm{~km}$ \\
\hline Single narrow-gauge railroads (760 mm) & $125 \mathrm{~km}$ \\
\hline Narrow-gauge station tracks & $13 \mathrm{~km}$ \\
\hline Wide-gauge station tracks (1520 mm) & $15 \mathrm{~km}$ \\
\hline Source: National Institute of Statistics & \\
\hline
\end{tabular}

The table 1 makes it clear that the total unfolded length of the railroad is $6474 \mathrm{~km}$, of which only 1976 $\mathrm{km}$ have been doubled. As majority of the railroads have been built over the last 20-30 years, they have 
speed limits due to their geographical parameters, the condition of the bottom building, the equipment and the track development at train stations.

\section{Analyzing the Age Structure of the Rolling Stock in Railway Cargo Transport}

BSR Cargo Freights Ltd. is the largest national railway transport carrier of dangerous goods, owning $70 \%$ of the rolling stock that operates within the country's transport system. The company has been in a precarious financial state for ten years, reporting negative results, which could be attributed primarily to the liberalization of the market for cargo freights, the strong competition from automobile cargo transport, and last but not least - the morally outdated rolling stock and the resulting necessity for its constant maintenance and repair. All of this contributes to the deterioration of safety and security during freight transport, lower quality of the supplied transport service and increased overall competitiveness of railway transport. Table 2 presents the age structure of the rolling stock of BSR Cargo Freights Ltd.

\begin{tabular}{|c|c|c|c|c|c|c|}
\hline \begin{tabular}{|l|} 
Type of Rolling \\
Stock
\end{tabular} & $\begin{array}{l}10-15 \\
\text { years }\end{array}$ & $\begin{array}{l}15-20 \\
\text { years }\end{array}$ & $\begin{array}{l}20-25 \\
\text { years }\end{array}$ & $\begin{array}{c}25-30 \\
\text { years }\end{array}$ & Over 30 years & Total \\
\hline Locomotives & - & - & 6 & 8 & 128 & 142 \\
\hline Freight wagons & & 23 & 107 & 1450 & 3315 & 4895 \\
\hline
\end{tabular}

The information presented in Table 2 makes it clear that nearly all locomotives in railway cargo transport $(90.14 \%)$ are over 30 years old, whereas the remaining 5.63\% are $25-30$ years old and only a small percentage (4.23\%) are 20-25 years old. It should also be taken into account that there are no locomotives in the 10-20-year age range. The table also shows a similar situation with freight-wagons: the majority of them $(67.72 \%)$ are morally outdated at over 30 years old, whereas the other vehicles (29.62\%) are 25-30 years old, and only an insignificant percentage (2.19\%) are 20-25 years old.

\section{Analyzing staff structure in railway cargo transport}

The age structure of staff working in cargo for National Company -"BSR - Cargo Freights" Ltd. by late 2019 is presented in table 3 as follows:

Table 3: Age composition of the staff by late 2019

\begin{tabular}{|l|l|l|}
\hline Age composition of the staff & Number & Relative share \% \\
\hline Total & 2745 & $100 \%$ \\
\hline 30 years and younger & 64 & $2.33 \%$ \\
\hline from 31 to 39 years & 252 & $9.18 \%$ \\
\hline from 40 to 49 years & 596 & $21.71 \%$ \\
\hline from 50 to 59 years & 1155 & $42.08 \%$ \\
\hline 60 years and older & 678 & $24.70 \%$ \\
\hline \multicolumn{2}{|l|}{ Source: National Company "BSR - Cargo Freights" Ltd. for 2019} \\
\hline
\end{tabular}

Source: National Company "BSR - Cargo Freights" Ltd. for 2019

Table 3 shows that of the staff working for the National Company-"BSR - Cargo Freights" Ltd. staff in the 50-59 age range constitute the largest relative share at $42 \%$.

The educational qualifications of people working in freight transport are presented in table 4 as follows:

\begin{tabular}{|l|r|r|}
\hline \multicolumn{3}{|c|}{ Table 4: Educational qualification of people working in railway cargo transport } \\
\hline Educational qualification & Number & \multicolumn{1}{|c|}{ Relative share \% } \\
\hline Total & 2745 & $100 \%$ \\
Primary education & 1 & $0.04 \%$ \\
\hline Basic education & 162 & $5.91 \%$ \\
\hline Secondary general education & 1049 & $38.21 \%$ \\
\hline Secondary special education & 642 & $23.39 \%$ \\
\hline Professional Bachelor & 428 & $15.59 \%$ \\
\hline Bachelor & 72 & $2.62 \%$ \\
\hline Master & 391 & $14.24 \%$ \\
\hline Source: National Company "BSR - Cargo Freights" Ltd. for 2019 \\
\hline
\end{tabular}

From Table 4 it can be seen that workers and employees with secondary and special education together constitute the majority relative share at $62 \%$. Staff with higher education - i.e. Bachelors and Masters together make up over 32\% (Tzvetkova \& Savova, 2019a). 


\section{Traffic accidents and incidents that occur during railway cargo transport}

Table 5 presents the number of accidents, injured people and casualties over the past 5 years which have resulted from collisions, derailment, accidents at railway crossings, accidents with people caused by moving vehicles, rolling stock catching fire, etc.

Table 5: Number of TA (traffic accidents) and casualties in railway transport for the 2014-2018 period

\begin{tabular}{|c|c|c|c|c|c|c|c|c|c|c|c|c|c|c|c|}
\hline & \multicolumn{3}{|c|}{2015} & \multicolumn{3}{|c|}{2016} & \multicolumn{3}{|c|}{2017} & \multicolumn{3}{|c|}{2018} & \multicolumn{3}{|c|}{2019} \\
\hline $\begin{array}{l}\text { Indicators: } \\
\text { TA - 1; } \\
\text { Casualties- 2; } \\
\text { Injured - 3 }\end{array}$ & 1 & 2 & 3 & 1 & 2 & 3 & 1 & 2 & 3 & 1 & 2 & 3 & 1 & 2 & 3 \\
\hline Total & 58 & 23 & 45 & 48 & 20 & 24 & 40 & 22 & 48 & 47 & 16 & 28 & 42 & 18 & 29 \\
\hline Collision & 4 & - & - & 3 & - & 2 & 3 & - & 0 & 1 & - & - & 1 & - & - \\
\hline Derailment & 6 & 1 & 8 & 6 & - & - & 6 & 7 & 29 & 5 & - & - & 1 & - & - \\
\hline $\begin{array}{l}\text { Accidents at railway } \\
\text { crossings }\end{array}$ & 11 & 6 & 16 & 6 & 2 & 7 & 5 & 5 & 5 & 11 & 5 & 9 & 5 & 4 & 6 \\
\hline $\begin{array}{l}\text { Accidents with people } \\
\text { caused by moving vehicles }\end{array}$ & 37 & 16 & 21 & 33 & 18 & 15 & 24 & 10 & 14 & 29 & 11 & 19 & 33 & 14 & 20 \\
\hline Rolling stock catching fire & - & - & - & - & - & - & 2 & - & - & 1 & - & - & 2 & - & - \\
\hline
\end{tabular}

Source: National Institute of Statistics

As per the above table, the actual number of people who were killed and injured in traffic accidents during railway cargo transportation was 68 in 2015, 44 in 2016 and went up to 70 in 2017. In 2018 there were 26 fewer casualties and injured people as compared to 2017, and in 2019 this total was 47 . In other words, a total of 273 people involved in railway transport have been killed or injured over the past 5 years.

\section{Inferences}

Table 1 presents data points concerning the condition of the railway network. This information makes it clear that railroads, including the ones that are part of the "main" and "wide-range" Trans-European Transport Network, are predominantly single and have therefore been built many years ago, which suggests that they have geometrical parameters, bottom building and equipment that have to conform with a $100 \mathrm{~km} / \mathrm{h}$ speed limit. With an average design speed of $105.2 \mathrm{~km} / \mathrm{h}$ for main railroads, the optimum velocity according to schedule is currently $85.2 \mathrm{~km} / \mathrm{h}$, meaning that there is a disparity of 20 $\mathrm{km} / \mathrm{h}$, which is considerable.

The analysis of data in Table 2 shows that the rolling stock has been operating within the national railway infrastructure for over 30 years and is therefore physically and morally obsolete, meaning that its maintenance requires a significant amount of resources. The mileage of most locomotives considerably exceeds permissible norms, and the locomotives themselves require a complete overhaul.

Tables 3 and 4 present the age composition and education of railway cargo transport employees. It is apparent that the majority of the staff are aging and only a small percentage of the employees have higher education.

Table 5 presents the number of traffic accidents involving railway cargo transport that have occurred in the country over the past five years. It shows how large the number of traffic accidents and correspondingly the number of people who have been killed or injured during this relatively short period of time is.

Overall, it can be concluded on the basis of the conducted analyses that railway freights of dangerous goods within the Republic of Bulgaria have low safety levels, which suggests that the freight process itself is hazardous to the environment. This in turn contributes to the poor quality and low social effectiveness of transport services. Immediate measures need to be taken to make the freight process, as well as all related accompanying activities, safer, more secure and more environmentally friendly.

\section{Measures for Improving Environmental Friendliness and Safety}

The primary measures and actions for protection from adverse incidents and hazards during the transportation of flammable or self-heating hard substances encompass various types of recommended extinguishing equipment such as fire extinguishing powder, carbon dioxide, foam and scattered water 
and outline the appropriate use of extinguishing agents. For instance, these measures articulate that extinguishing water must only be fed in the tanks after the molten naphthalene has cooled down to $93^{\circ} \mathrm{C}$ so that it does not come out in an explosive manner; water or foam should be fed carefully in molten naphthalene in order to avoid the formation of a thick crust. Additionally, there must be measures for complete personal protection i.e. thorough protection of the body by means of a protective suit and a breathing apparatus which is independent from the surrounding environment. Measures of liquidation of accidents are outlined, which articulate that all sources of fire should be removed from the dangerous zone. For instance, Naphthalene is prone to thermal self-ignition; Naphthalene vapors can ignite when the air gets heated or are easily set ablaze by the flame of a matchstick. Thus Naphthalene smelt should not be moved forward with compressed air as the deposited dust is highly inflammable and combustion holds a risk of explosion. Measures cover the necessity for evacuation, as substances might pose considerable danger to the surrounding area. It is imperative that evacuation measures be taken right at the start of the accident (Varadinova, 2009). The conducted analyses have determined the necessity for improving freight safety and reducing the potential for occurrence of accidents and disasters that affect the environment negatively. These analyses suggest, first and foremost, improving the railroads, improving related equipment, and providing the necessary technical services and repairs for them. Another vital factor for the achievement of freight safety is the imperative renewal, upgrade and modernization of the rolling stock, as well as the introduction of contemporary systems for organizing and managing the freight process. This in turn will help elevate and maintain employees' competence, motivation and satisfaction. This will lead to significant improvements in the quality of transport services and working conditions in order to eliminate all work-related hazards. For example, the integration of Intelligent Transport Systems covers a wide range of technical decisions whose purpose is to perfect transport by improving mobility and increasing railway traffic safety. Abiding by standards such as high qualification, necessary education, physical and psychological qualities of employees according to the specificity of each individual activity, as well as the implementation of the necessary measures for observing discipline and rules during the overall freight process, loading and unloading activities will guarantee the preservation of the consumer value of the cargo and freight safety. Other essential measures that should be adopted involve measures for the construction of new terminals, cargo centers and logistic centers which also specialize in loading and unloading activities for dangerous goods (Tzvetkova \& Savova, 2019b). The creation of effective logistic chains requires optimal combination of individual types of transport, as well as exchange of good practices for improving the standardization and interoperability between railway transport and automobile transport. It should be noted that railway transport is the most environmentally friendly means of transporting dangerous goods by land, despite this, at present, the balance between automobile transport and railway transport has shifted in favor of automobile transport, which is at odds with the EU's priorities and affects the environment permanently in a negative way. The development of a new Republican Transport Plan will contribute to the coherent development of individual types of transport without giving advantage to one type over another. The integration of Bulgaria's transport system into the European one will help improve and develop infrastructural connections, achieve interoperability, attract international traffic through the country and increase the competitiveness of Bulgarian transport firms.

\section{Conclusion}

Safe and environmentally-friendly railway transport freights of dangerous goods are crucial for the effective functioning of transport activities. People who use transport services expect a safe and secure transport process, as well as the complete preservation of the consumer value of the transported cargo. The objectives regarding safety include the following fundamental directions: ensuring passenger safety during railway transport freights; operating railway transport in conditions of calamity and crises of various kinds; preparing internal normative documents concerning the safety and reliability of railway transport; developing measures to counteract terrorist threats and reducing any negative consequences resulting from them (Varadinova \& Stoyanov, 2011). One of the roles of the European Commission at a European level is to meet these expectations by guaranteeing that the necessary standards for safety, security and environmental friendliness have been established across the entirety of the EU. These requirements have become considerably more important in recent years, given the unstable international situation and the increased risk of terrorist activities on an international scale. The incidents that have occurred in recent years during railway transport freights of dangerous goods have resulted in multiple 
human casualties and irreparable damage to the environment. Despite the technical and technological advances of modern society, accidents involving human casualties, considerable damage to material and threats to environmental balance are still quite a common occurrence. This encompasses all fields of activity including industry, services and transport among others. Questions such as "Why did it happen?" and "What can be done to prevent it from happening again?" are natural reactions that result from such incidents. (Georgiev, 2002). Bulgaria needs to adopt emergency measures and make significantly larger efforts to adhere to the high safety levels implemented in Western Europe, as well as implement purposeful active policies to prevent the occurrence of undesirable events.

\section{References}

Development of the "Bulgarian State Railways Holding" 2015-2022, https://transportal.bg/plan-za-ozdravyavane-i-razvitiena-holding-bdzh-ead-za-2015-2022-g/

Ganev, R., Varadinova, Yu., Zhelezov, E. (2011), ADR Agreement and Analysis of a Fire Involving a Truck Loaded with Gunpowder, Ministry of Interior - Academy of the Interior Ministry, Sixth Scientific Conference with International Participation Civil Safety 2011, March 24-25, 2011, pp. 23-30, ISSN 1313-770

Georgiev, N., (2002), Management - A Fundamental Alternative for Complex and Systematic Solutions to the Problems of Railway Safety, 12th Scientific Conference with International Participation - TEMPT 2002, VTU, Sofia, 14-15.11.2002, Compendium of Reports, pp. 449-454

Integrated Transport Strategy Until 2030. Ministry of Transport, Information Technology and Messages, pp. 177- 179, https://www.mtitc.government.bg/sites/default/files/integrated_transport_strategy_2030_bg.pdf

National Statistics Institute: www.nsi.bg

Nikolov, N. (2015), Transporting Dangerous Cargo by Railway, Scientific Journal: Mechanics, Transport, Communications, Sofia, Vol. 13, Issue 3/1, 2015, article 1164, pp. II-53-II-54, ISSN: $2367-6620$

Railway Transport in Bulgaria, https://bg.wikipedia.org/wiki/Железопътен_транспорт_в_България

Regulations Concerning the International Carriage of transport, www.tsoshop.co.uk.

Tzvetkova S., Savova E. (2019a), Financial instruments for sustainable development of "BSR - Cargo Freight Ltd.", Scientific journal: Mechanics, Transport Communications, Vol. 17, Issue 3, 2019, part 1, ISSN: 13123823 (print), ISSN 23676620 (online), article 1805, pp. III-82 - III - 89

Tzvetkova S, Savova E, (2019b), The Necessity to Improve the Competitive Power of "Bulgarian State Railways - Cargo Freights Ltd.”, Journal of Advanced Management Science, June 2019, Vol. 7, №2, pp. 77-83, doi: 10.18178/joams.7.2.77-83

Varadinova, Yu., (2009), Characterization, Classification and Actions During Incidents Involving Representatives of Classes3, 4.1, 4.2 and 4.3 According to ADR, Scientific Journal: Mechanics, Transport, Communications, Issue 3/2009, pp. 134141 , ISSN 1312-3823

Varadinova, Yu., Stoyanov, I. (2011), Bezopasnost v zheleznodorozhnom transporte, IV International Scientific - Practical Conference: The Safety of Human Life as a Prerequisite/Condition for the Stable, Proceedings of Conferences in Kiev, Ukraine, 08-10.06.2011, ISBN 978-966-699-639-1

Zhelezov, E., Vassilev, D., Todorova, D., Ananiev, S., Varadinova - Milkova, Yu., (2010), Transport of dangerous goods by land transport, Sofia, ISBN 978-954-12-0191-6 